\title{
Manejo florestal comunitário na Amazônia: comparação entre um modelo introduzido e a extração ilegal de madeira
}

\section{Community forest management in the Amazon: comparison of an introduced model and illegal timber extraction}

Philippe Waldhoff - Doutor em Recursos Florestais pela Universidade de São Paulo (USP). Professor no Instituto Federal de Educação, Ciência e Tecnologia do Amazonas (IFAM). E-mail: philippe.tim@gmail.com

Edson Vidal - Doutor em Ciências da Engenharia Ambiental, pela Universidade de São Paulo (USP). Professor do Departamento de Ciências Florestais da Escola Superior de Agricultura Luiz de Queiroz (ESALQ/USP). E-mail: edson.vidal@usp.br

\section{Resumo}

A extração de pequenas quantidades de madeira faz parte dos meios de vida de diversas comunidades tradicionais na Amazônia. A exigência da licença ambiental trouxe enormes desafios para seus protagonistas, colocando muitos em uma situação de clandestinidade. Foi comparada a situação entre extratores que adotaram as regras formais do plano de manejo florestal e os que permaneceram extraindo de forma convencional. Foram realizadas entrevistas e análise documental. Os dados foram analisados utilizando-se a base conceitual dos meios de vida sustentáveis, estatística descritiva e testes de análise de variâncias. A extração de madeira com plano de manejo florestal apresentou melhores resultados em relação ao capital natural e piores em relação ao capital financeiro e físico. Concluiu-se que a adoção das regras do manejo florestal sustentável contribui para a conservação da floresta e das espécies manejadas, mas levaram à irregularidade da renda e a dependência financeira de agentes externos.

\section{Keywords}

Extração de Madeira. Amazônia. Meios de Vida. Licenciamento Ambiental.

\begin{abstract}
Small-scale logging forms part of the livelihoods of many traditional communities in the Amazon. However, the requirements of environmental licensing have caused enormous challenges for loggers, putting many in a situation of clandestine extraction. The situation between loggers who have adopted the formal rules of forest management plans and those who have continued to extract conventionally was compared. Interviews and document analysis were conducted, and the data were analyzed using the conceptual basis of sustainable livelihoods, descriptive statistics and analysis of variance. Timber extraction with a forest management plan showed better results with regard to natural capital and worse results for financial and physical capital. We conclude that adoption of sustainable forest management rules contributed to conservation of the forest and of managed species but led to income irregularity and financial dependence on external agents.
\end{abstract}

\section{Palavras-chave}

Timber Extraction. Amazonia. Livelihoods. Environmental Licensing. 


\section{INTRODUÇÃO}

Foi com o Decreto no 1.282 de 1994, que se definiu pela primeira vez, em termos legais, o que seria o manejo florestal sustentável e quais seriam os seus princípios e diretrizes para a Amazônia brasileira. A partir de então, houve diversas regulamentações sobre o manejo florestal sustentável (BRASIL, 2007), sendo que, em 1998, foram criadas normas específicas para o Manejo Florestal Comunitário (MFC) (CARVALHEIRO et al., 2008). Para Sunderlin (2006), quando o MFC é estabelecido por meio de normas elaboradas e apresentadas por agentes externos às comunidades, pode ser qualificado como um "modelo introduzido" de MFC. O modelo introduzidoé, via de regra, caracterizado por uma abordagem fortemente influenciada pelo manejo florestal sustentável concebido para as empresas florestais (POKORNY; JOHSON, 2008), enfatizando aspectos regulatórios e legais (JONG et al., 2010).

A normatização do manejo florestal, somada a uma forte pressão para diminuir as taxas de desmatamento na Amazônia, fez com que diferentes atores sociais viessem a buscar a regularização da atividade de extração de madeira (STONE-JOVICICH et al., 2007; WALDHOFF; VIDAL, 2015). A não obediência às normas ambientais, seja pela falta de condições ou de interesse em extrair e comercializar madeira de forma legal, dá origem aos extratores clandestinos e a madeira ilegal.

Com o objetivo de fortalecer a cadeia produtiva florestal e inserir os extratores de caráter familiar/comunitário no escopo da legalidade, iniciou-se em 2003, no estado do Amazonas, um programa para apoiar o desenvolvimento de Planos de Manejo Florestal Sustentável de Pequena Escala (PMFSPE) (KIBLER; SILVA, 2008). Esses mesmos autores identificaram uma série de fatores que dificultavam o bom funcionamento desse programa, como a grande distância entre os projetos e os órgãos ambientais. Para Hajjar et al. (2011), as exigências estabelecidas para a elaboração e aprovação dos planos de manejo têm se mostrado muito complexas e fora do contexto das comunidades rurais.

A falta dos direitos de uso e propriedade das terras são fatores que podem, logo no início, inviabilizar as iniciativas de MFC (HAJJAR et al., 2011). Alguns projetos, quando já estabelecidos, contribuíram efetivamente para a melhoria das condições de vida e diminuição da pobreza (CHEN et al., 2013; RADACHOWSKY et al., 2012), proferindo benefícios econômicos, socioculturais 
e ambientais (HAJJAR et al. 2011). Por outro lado, muitos estudos têm apontado para as limitações ou mesmo a inviabilidade financeira do MFC (KOURY, 2007; CARVALHO; OLIVEIRA, 2010; MEDINA; POKORNY, 2011; HUMPHRIES et al., 2012).

Foram aplicados muitos recursos por meio de diferentes programas e projetos na busca de promover e viabilizar o modelo introduzido de MFC, destacando-se o Programa Piloto para a Proteção das Florestas Tropicais do Brasil (PPG-7) (AMARAL NETO et al., 2011). Apesar dos esforços multilaterais, milhares de comunitários e pequenos produtores familiares continuaram a extrair madeira de forma clandestina. Quais os motivos que levam a permanecer na clandestinidade? Poucos estudos têm se debruçado sobre o ponto de vista dos pequenos produtores. Será que o modelo introduzido de MFC é uma opção viável, considerando os meios de vida desses atores sociais? O objetivo desta pesquisa foi o de comparar os resultados alcançados pelo modelo introduzido de MFC em relação à extração clandestina, sobre os meios de vida de seus protagonistas, buscando ampliar a compreensão sobre os motivos que mantêm os extratores à margem da legalização.

\section{MATERIAL E MÉTODOS}

\section{1 ÁREA DA PESQUISA}

A pesquisa foi desenvolvida no município de Boa Vista do Ramos (BVR), a $270 \mathrm{~km}$ de Manaus, na região denominada de Médio Amazonas, à margem direita do rio Amazonas. A escolha deste município deveu-se ao apoio ofertado pela unidade local do Instituto de Desenvolvimento Agropecuário e Florestal Sustentável do Amazonas (IDAM), responsável pela assistência técnica florestal, que possibilitou o acesso aos PMFSPE e o estabelecimento de contato com extratores clandestinos.

O município apresenta um histórico de extração de madeira superior a 50 anos. Em 1999, um levantamento do setor produtivo identificou mais de 250 pessoas vinculadas ao processo de extração de madeireira (KOURY, 2007). Alguns destes extratores formaram a Associação Comunitária Agrícola e de Extração de Produtos da Floresta que protagonizou o primeiro projeto de "modelo introduzido" de MFC no município (WALDHOFF, 2014; MEDINA; POKORNY, 2011). 
Em 2006, teve início na região, dentro do escopo das políticas públicas estaduais, o Projeto Floresta Viva, com o objetivo de fortalecer o Programa Estadual de Manejo Florestal em Pequena Escala, com ações direcionadas à organização social, ao desenvolvimento de capacidade técnica e à estruturação da cadeia de comercialização da madeira manejada (KIBLER; SILVA, 2008). Em 2009, o estado do Amazonas passou, por meio do IDAM, a oferecer assistência técnica florestal aos pequenos produtores de BVR. O IDAM também oferece apoio no trâmite do licenciamento ambiental junto ao Instituto de Proteção Ambiental do Estado do Amazonas e na comercialização da madeira manejada.

\subsection{LEVANTAMENTO DE DADOS}

Esta pesquisa baseou-se em um Experimento Natural (BERNARD, 2006), onde foi comparado o efeito do Programa Estadual de MFC do Estado do Amazonas sobre dois grupos de extratores de madeira: os que adotaram o PMFSPE e os que não adotaram (doravante denominados como "extratores clandestinos"). A comparação foi realizada com base no marco analítico dos "meios de vida sustentáveis" (sustainable livelihoods framework), que compreendem os recursos (capital humano, social, natural, físico e financeiro), as atividades e o acesso a estes (mediados pelas relações institucionais e sociais) que juntos determinam os ganhos individuais ou familiares (DFID, 1999).

Os dados foram coletados nos anos de 2013 e 2014 por meio de entrevistas, conforme sugerido em Gil (2008). Foram realizadas entrevistas não estruturadas com o diretor florestal do IDAM, o técnico florestal da unidade local do IDAM no município de BVR e o presidente da Associação de Manejadores Florestais do Curuçá.

Foi realizada uma amostragem com base em dois grupos de indivíduos: os extratores com PMFSPE (considerado aqui como o modelo introduzido de MFC) e os extratores clandestinos. Os indivíduos entrevistados foram escolhidos por julgamento de forma a se obter amostras comparáveis (BARBETTA, 2012), utilizando-se como critério, extratores que já tinham realizado a comercialização de madeira. Uma das amostras foi extraída a partir dos 55 detentores de PMFSPE localizados no município de BVR (base de dados do IDAM). Desses, 17 já haviam comercializado madeira manejada (considerada neste trabalho, como a madeira oriunda de projeto de manejo florestal licenciado) e 14 ( $n=14)$ 
foram entrevistados. A outra amostra foi selecionada a partir da Associação dos Profissionais da Motosserra que congrega aproximadamente 84 extratores clandestinos de madeira, dos quais $19(\mathrm{n}=19)$ foram entrevistados.

Cada um dos extratores de madeira inseridos na amostragem foi entrevistado sobre diferentes aspectos relacionados aos capitais (humano, social, físico, financeiro e natural) dos meios de vida, por meio de um roteiro semiestruturado. As respostas foram categorizadas em escala ordinal de cinco pontos: muito negativo; negativo; neutro; positivo; muito positivo (KUSTERS et al., 2005).

\subsection{ANÁLISE DE DADOS}

As entrevistas não estruturadas foram analisadas de forma qualitativa visando a uma maior clareza do processo político e de produção, contribuindo para a discussão do trabalho. As entrevistas estruturadas foram analisadas por meio de estatística descritiva e comparação de média referente a cada capital.

Cada categoria da escala ordinal encontrada nas respostas dos extratores foi transformada em valores numéricos: muito negativo $=0$; negativo $=0,25$; neutro $=0,5 ;$ positivo $=0,75$ e muito positivo $=1$. A partir das perguntas referentes a cada capital, foi determinado, com base na média aritmética simples, um único valor do capital para cada entrevistado (Valor Médio Individual do Capital (VIC) - eq. (1)).

$$
\begin{gathered}
\mathrm{n} \\
\mathrm{VIC}=\sum \mathrm{i} / \mathrm{n} \\
\mathrm{i}=1
\end{gathered}
$$

Onde o Vic $=$ valor médio individual da capital; $\mathrm{i}=$ valor do indicador; $\mathrm{n}$ $=$ número de indicadores.

A partir da média aritmética simples de cada entrevistado (VIC) foi determinado o Valor Médio Total do Capital (VTC) (eq. (2)) com base em todas as entrevistas para cada uma das situações estudadas: extratores com PMFSPE e extratores clandestinos

n

$$
\begin{array}{r}
\mathrm{Vtc}=\sum \mathrm{Vic} / \mathrm{n} \\
\text { Vid }=1
\end{array}
$$


Onde Vtc $=$ Valor médio total do capital; Vic $=$ valor médio individual do capital; $\mathrm{n}=$ número de entrevistas.

As médias referentes a cada capital (VTC) de cada situação foram comparados utilizando-se diferentes métodos de ANOVA - TTEST; Wilcoxon Two-Sample Test; Kruskal-Wallis - de acordo com os resultados dos testes de normalidade (Shapiro Wilk) e de homocedasticidade.

\section{RESULTADOS}

A extração de madeira realizada por meio de PMFSPE apresentou resultados diferentes no capital natural, físico e financeiro, em relação à extração clandestina. Nos capitais humano e social não foram identificadas diferenças significativas (Figura 1).

O capital natural mostrou-se significativamente melhor para os extratores com PMFSPE (Qui-quadrado = 21.4171; G.L $=1$; $\operatorname{Pr}>$ Qui-quadrado < 0,0001). O capital financeiro e o físico apresentaram melhores resultados para os extratores clandestinos (G.L $=30$; valor de $\mathrm{t}=2,27$; valor de $\mathrm{p}=0,0307$; Quiquadrado = 6.7926; G.L = 1; $\operatorname{Pr}>$ Qui-quadrado = 0,0092). O capital humano e o social não apresentaram diferenças significativas $(G . L=31$; valor de $\mathrm{t}=-0,70$; valor de $\mathrm{p}=$ 0,4488; G.L $=31$; valor de $\mathrm{t}=-1,62$; valor de $\mathrm{p}=0,1157$ ).

Figura 1 - Pentagrama comparando os resultados da extração de madeira sobre os meios de vida entre os extratores com PMFSPE e os extratores clandestinos

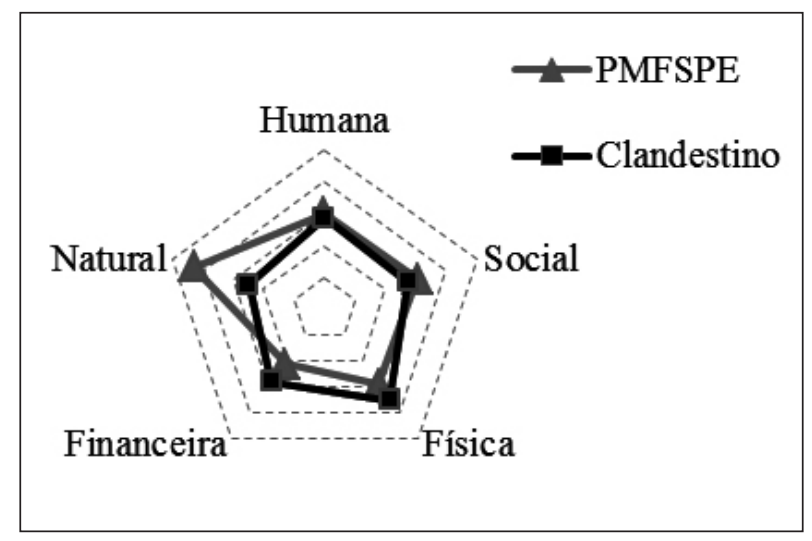

Os capitais podem ser representados por seus indicadores específicos permitindo uma melhor análise e interpretação dos resultados (Tabela 1). 


\section{DISCUSSÃO}

Os resultados do trabalho mostraram que o modelo introduzido de $\mathrm{MFC}$, da forma em que vem sendo aplicado, não tem sido efetivo para melhorar os meios de vida dos extratores. A discussão que se segue é focada nos capitais e seus respectivos indicadores.

\subsection{CAPITAL HUMANO}

Os extratores com PMFSPE se destacaram principalmente em relação ao desenvolvimento de novos conhecimentos, em especial, na adoção de práticas relacionadas ao Manejo Florestal de Impacto Reduzido (DYKSTRA, 2002) como: o uso de equipamentos individuais de segurança; o uso de trilhas de fuga; técnicas de mapeamento e inventário florestal; teste de verificação das árvores ocadas; derruba direcionada da árvore. As práticas adotadas além de serem importantes para a segurança dos trabalhadores contribuem com a manutenção da floresta manejada (MACPHERSON et al., 2010). O desenvolvimento das habilidades relacionadas ao manuseio da floresta faz parte de um contexto mais fácil de ser assimilado pelos extratores. No entanto, em relação ao processo de produção, o estabelecimento de PMFSPE exige conhecimentos relacionados ao processo de licenciamento ambiental e comercialização de madeira legalizada, fora do contexto usual dos extratores.

Tabela 1 - Comparação entre os valores médios encontrados para cada capital e os respectivos indicadores

\begin{tabular}{|c|c|c|c|c|c|}
\hline \multirow{2}{*}{$\begin{array}{l}\text { Capital } \\
\text { (Cap.) }\end{array}$} & \multirow{2}{*}{ Indicador (Ind.) } & \multicolumn{2}{|c|}{ PMFSPE } & \multicolumn{2}{|c|}{ Clandestino } \\
\hline & & Ind. & Cap. & Ind. & Cap. \\
\hline \multirow{3}{*}{ Natural * } & Conservação dos recursos manejados & 0,75 & 0,86 & 0,33 & 0,50 \\
\hline & $\begin{array}{l}\text { Controle de acesso aos recursos } \\
\text { manejados }\end{array}$ & 0,93 & & 0,67 & \\
\hline & Conservação da floresta & 0,89 & & 0,51 & \\
\hline \multirow{6}{*}{ Humano } & Segurança no trabalho & 0,68 & 0,6 & 0,42 & 0,57 \\
\hline & Alimentação no trabalho & 0,57 & & 0,51 & \\
\hline & Educação formal & 0,50 & & 0,49 & \\
\hline & Uso de conhecimentos tradicionais & 0,61 & & 0,72 & \\
\hline & Acesso a novos conhecimentos & 0,73 & & 0,68 & \\
\hline & Conhecimento do processo de produção & 0,50 & & 0,59 & \\
\hline
\end{tabular}




\begin{tabular}{|c|c|c|c|c|c|}
\hline \multirow{5}{*}{ Social } & Oportunidade para jovens & 0,55 & 0,61 & 0,57 & 0,55 \\
\hline & Relações internas da comunidade & 0,59 & & 0,53 & \\
\hline & Participação na organização & 0,68 & & 0,41 & \\
\hline & Empoderamento feminino & 0,55 & & 0,70 & \\
\hline & Relações externas & 0,66 & & 0,56 & \\
\hline \multirow{3}{*}{ Físico* } & Infra local (comunitária) & 0,50 & 0,58 & 0,57 & 0,70 \\
\hline & Eletrodomésticos e infra da casa & 0,63 & & 0,76 & \\
\hline & Equipamentos e infra do trabalho & 0,58 & & 0,76 & \\
\hline \multirow{4}{*}{ Financeiro* } & Agregação de valor e qualidade & 0,83 & 0,43 & 0,39 & 0,55 \\
\hline & Regularidade da renda & 0,25 & & 0,64 & \\
\hline & Divisão da renda & 0,60 & & 0,67 & \\
\hline & Independência financeira & 0,16 & & 0,50 & \\
\hline
\end{tabular}

* Capitais que apresentaram diferenças estatísticas entre as médias O valor do capital apresentado na tabela representa a média simples dos indicadores

Os extratores clandestinos se destacaram em relação ao uso dos conhecimentos tradicionais, que são a base para o desenvolvimento do trabalho. Devido ao histórico de desenvolvimento do modelo introduzido de MFC na região, os extratores clandestinos também tiveram um bom acesso aos novos conhecimentos. Foi identificado que 36\% desses realizam práticas de manejo florestal sustentável.

\subsection{CAPITAL SOCIAL}

O desenvolvimento de projetos do modelo introduzido de MFC na região, desde o final dos anos 1990, levou a uma organização formal para a atividade. Foi identificado que a maioria dos extratores com PMFPE são membros da Associação de Manejadores Florestais do Curuçá e 60\% dos extratores clandestinos fazem parte da Associação dos Profissionais da Motosserra. No entanto, os extratores com PMFSPE são mais atuantes junto à sua associação e tiveram suas relações com instituições externas, em especial o IDAM, fortalecidas, e ampliadas para novos grupos de compradores de madeira legalizada.

A extração de madeira, via de regra, não interferiu nas relações internas das comunidades e se apresentou como uma oportunidade limitada para os jovens. As mulheres quando no contexto dos PMFSPE estiveram limitadas a serem 
legalmente as proponentes dos projetos, mas não tiveram envolvimento efetivo com o trabalho. Na extração clandestina, as mulheres estiveram mais presentes e foram remuneradas pelo trabalho.

\subsection{CAPITAL FÍSICO}

De uma forma geral não foram identificados investimentos relacionados à infraestrutura comunitária, caracterizando uma cadeia produtiva com poucos investimentos privados ou públicos. O capital físico refletiu a capacidade de compra ou de investimentos que os extratores têm sido que a renda proveniente da extração de madeira é aplicada em bens domésticos e na manutenção e compra de materiais de trabalho. Em ambos os casos, os extratores clandestinos apresentaram uma maior capacidade de compra ou investimento.

\subsection{CAPITAL NATURAL}

O capital natural foi o que apresentou a maior diferença, a favor do PMFSPE, entre as duas situações estudadas. Em parte, o fato está relacionado às características conservacionistas prescritas na legislação ambiental e que devem ser adotadas nas áreas dos PMFSPE (AMAZONAS, 2011).

\section{Conservação das espécies manejadas}

No caso do PMFSPE, a obrigatoriedade de manutenção de árvores, que em outros casos seriam exploradas, para o segundo ciclo de produção ou como porta sementes, contribui, na percepção dos extratores, diretamente com a conservação das espécies manejadas.

A extração clandestina pode ocorrer em duas situações. Na primeira, a floresta é mantida, sendo feita apenas a extração seletiva das espécies comerciais. A segunda ocorre em áreas onde a floresta foi derrubada para o estabelecimento de roça ou pasto, fazendo-se o aproveitamento das espécies de interesse. Em ambos os casos, não foram constatadas regras formais ou informais que visem conservar os recursos manejados.

Os relatos feitos por extratores apontam para a sobre exploração das algumas espécies comerciais indicando uma tendência da "tragédia dos comuns" (HARDIN, 1968). Como exemplos foram citados a Cedrela fissilis (cedro) e o 
Aniba rosaeodora (pau-rosa), duas espécies intensamente extraídas anteriormente e que quase não são mais encontradas nas florestas da região. No entanto, deve-se atentar ao fato de que a floresta, como um todo, mostrou-se capaz de atender à demanda de produção dos comunitários com base em novas espécies comerciais.

\section{Controle de acesso aos recursos manejados}

A formalização do PMFSPE requer o mapeamento da propriedade, a demarcação da área onde será realizada a extração de madeira, a abertura de trilhas e a identificação das árvores que serão exploradas. Esses procedimentos permitem um controle bastante eficiente da área e do acesso aos recursos. No caso da extração clandestina, quando ocorre em áreas privadas onde a floresta é convertida em outros usos, o proprietário pode determinar os extratores que irão fazer o aproveitamento das árvores comerciáveis, mas não há preocupação com o controle sobre os recursos florestais como um todo. Já, quando a extração clandestina ocorre em áreas das comunidades, podem existir regras que excluam outras pessoas que não são membros da comunidade, como é o caso das propriedades comunais apontado por Feeny et al. (2001).

\section{Conservação da floresta}

As áreas com os PMFSPE foram devidamente cadastradas no órgão ambiental competente (IPAAM) e ficaram proibidas de serem convertidas em outros usos (BRASIL, 2012). Os extratores mostraram claro entendimento sobre esta situação, sabendo que essas áreas não podem ser utilizadas para roçados ou pastagens, aumentando as possibilidades de manutenção da floresta.

Nas áreas onde ocorre a extração clandestina, não existem garantias formais ou informais de que essas áreas permanecerão como florestas. Muitas vezes, inclusive, a madeira é extraída em áreas que já foram derrubadas para outros usos. Apesar desta situação crítica, foi identificado que alguns extratores percebem a importância da manutenção da floresta como uma fonte de recursos.

\subsection{CAPITAL FINANCEIRO}

Agregação de valor e qualidade

Esse indicador apresentou um valor superior para os extratores com PMFSPE, pois a madeira de origem manejada, pelo fato de vir acompanhada dos 
documentos de origem ambiental e fiscal, apresentou um maior valor de venda. Também, os extratores com PMFSPE, fizeram uso de serraria portátil para o desdobro da madeira, o que resultou em um produto de melhor qualidade. Os extratores clandestinos vendem por preços menores, pois não têm os documentos de origem da madeira e fazem o desdobro com motosserra, que resulta em uma qualidade pior e gera mais desperdícios.

Em BVR, 95\% dos extratores clandestinos vendem a madeira na forma de produtos processados para uso direto principalmente para a construção civil (moradias). Já os extratores com PMFSPE, vendem a madeira processada, porém com dimensões maiores, principalmente para movelarias locais e regionais. Contrapondo estimativa de que menos de $10 \%$ dos pequenos produtores na Amazônia, comercializam produtos florestais processados (VOS et al., sem data, apud JONG et al., 2010). Os resultados mostraram um importante potencial dos produtos semiacabados e acabados para os mercados locais e regionais, muitas vezes desconsiderada no contexto dos MFC.

\section{Divisão da renda}

Nas duas situações estudadas, a divisão a renda auferida com a venda da madeira ficou de posse do detentor do PMFSPE ou do responsável pela extração clandestina. Os demais trabalhadores envolvidos foram pagos mediante diárias. Não foram identificadas melhorias ou alocação de recursos, com a renda proveniente da venda da madeira, nas comunidades ou em instâncias coletivas.

\section{Regularidade da renda}

A falta de regularidade ou, em outros termos, a irregularidade da renda, pode ser apontada como um dos principais problemas relacionados aos extratores com PMFSPE. Em BVR, os PMFSPE começaram a ser elaborados em 2005/2006. Até a época da pesquisa haviam sido elaborados 55 planos de manejo (banco de dados do IDAM-BVR). Desses, aproximadamente 30\% chegaram à comercialização e apenas 7\% fizeram mais de uma venda. Portanto, mesmo quando os extratores com PMFSPE alcançaram renda com a venda da madeira manejada, pouquíssimos projetos conseguiram fechar o ciclo de produção e venda mais de uma vez, principalmente devido aos aspectos burocráticos e legais, que serão discutidos nas considerações complementares. 
No caso dos extratores clandestinos, apesar do risco por terem praticado uma atividade ilegal, a extração de madeira resultou em uma renda regular inserida no planejamento pessoal/familiar passível de entradas mensais.

\section{Independência financeira}

Os extratores com PMFSPE apresentaram uma alta dependência financeira para realizar da atividade, pois não possuíam condições de arcar com os custos associados ao apoio técnico, administrativo e burocrático recebido para elaboração e tramitação dos PMFSPE. De acordo com Pokorny e Johnson (2008), as limitações impostas por estes fatores acabam inviabilizando os projetos.

Os extratores clandestinos apresentaram uma alta autonomia refletindo em uma boa pontuação na independência financeira. O fato está relacionado aos poucos recursos necessários para o trabalho, condizentes com as circunstâncias do extrator, que depende mais de sua própria força de trabalho e, nesse caso, de alguns poucos gastos relacionados ao uso e manutenção das motosserras.

\section{Considerações complementares sobre os obstáculos financeiros}

De uma forma geral, os projetos do modelo introduzido de MFC na região amazônica se mostraram pouco atrativos em relação às perspectivas de retorno financeiro (POKORNY; JOHNSON, 2008; CARVALHO; OLIVEIRA, 2010; JONG et al., 2010; MEDINA; POKORNY, 2011; HUMPHRIES et al., 2012). Alguns dos fatores apontados foram: altos investimentos iniciais; baixa produtividade; alto custo de produção, baixo preço de venda; distância de mercados; desafios logísticos e de gestão, entre outros. Uma análise dos resultados do presente trabalho permite trazer novos elementos para a discussão.

\section{Tempo de espera para transformar um recurso natural em ativo financeiro}

Para os extratores clandestinos, a madeira é uma forma rápida de transformar um recurso natural em ativo financeiro, se mostrando adequada aos seus meios de vida. Infortunadamente, para os extratores legalizados (com PMFSPE), a transformação de um recurso natural para ativo financeiro, não é garantida e quando ocorre é demorada.

O processo de regularização ambiental é caracterizado por um período inicial, entre 2 e 3 anos, em que o interessado tem diversos gastos para elaborar o 
plano de manejo e demais procedimentos administrativos, e tramitá-lo junto aos órgãos competentes (WALDHOFF; VIDAL, 2015). Durante esse período existe uma grande incerteza, pois não se sabe quando e se será obtida a licença ambiental. Somente após obter a licença poderão ser realizadas as operações de exploração e transporte da madeira, e estabelecidos os acordos comerciais. Em BVR dentre os 55 PMFSPE identificados no período desta pesquisa, apenas 17 chegaram à comercialização da madeira. Essa demora na tramitação documental eleva muito o tempo de aprovação do plano e, em muitos casos, acaba por desestimular o pequeno manejador, fomentando a ilegalidade (VIANNA et al., 2013).

\section{Comercialização da madeira}

A comercialização da madeira oriunda dos PMFSPE é um processo que requer o acesso à Rede Mundial de Computadores, dentro de um sistema gerenciado pelo IBAMA, denominado de Sistema DOF (Documento de Origem Florestal) (BRASIL, 2007). O DOF consiste em um sistema de crédito de madeira baseado no volume por espécie, devidamente autorizada na licença ambiental. $\mathrm{O}$ processo de venda e compra é realizado virtualmente, sendo que o transporte da madeira só é liberado quando o vendedor (neste caso extrator com PMFSPE) inserir diversas informações no sistema, inclusive o número do Documento/ Nota Fiscal, e solicitar a emissão do DOF. A partir de então fica estabelecido um prazo para a realização da tramitação física da madeira. O volume comercializado passará a ficar creditado para o comprador. Em BVR, somente 7\% dos extratores com PMFSPE e 18\% dos extratores clandestinos, entrevistados, utilizam computador e têm acesso à internet. Portanto, para os grupos estudados, a venda da madeira manejada depende de terceiros para ser realizada.

Um segundo fator limitante para a comercialização de madeira manejada está relacionado à identificação de compradores. Os compradores de madeira manejada, sendo movelarias ou qualquer tipo de entreposto ou indústria, precisam estar cadastrados no Sistema DOF, ter licença ambiental e as certidões negativas de débitos fiscais atualizadas; caso contrário, as comercializações não podem ser realizadas. Esta exigência restringe as opções de compradores, pois poucos estabelecimentos se encontram plenamente aptos a comprarem madeira manejada.

Somado aos aspectos transacionais, a venda da madeira ainda tem um desafio imposto por questões ambientais. As chuvas durante o período de inverno prejudicam a derruba das árvores e o transporte inicial da madeira. Por outro 
lado, no período da seca os rios ficam com o nível da água baixo e as áreas com PMFSPE podem se tornar inacessíveis. Portanto, após obtida a licença ambiental, os extratores com PMFSPE, tiveram de realizar todo o processo de extração e transporte da madeira, encontrar compradores viáveis e operacionalizar o sistema DOF, tudo isso, em um espaço de tempo em que as condições climáticas e ambientais, permitissem o desenvolvimento destas ações. Ficou evidente que os processos de regulação da atividade de base florestal são inadequados para a realidade da produção e manejo comunitários, como apontado anteriormente por Benatti et al. (2003).

Em contraponto, os extratores clandestinos operam dentro de um sistema completamente inserido na informalidade, sem os documentos fiscais e as licenças ambientais, pautado nas necessidades e capacidades pessoais do extrator. Um simples processo de compra e venda realizado diretamente com um atravessador ou o consumidor final, sem burocracia e sem custos, mas com um ônus ambiental e fiscal. A ilegalidade da atividade madeireira global na Amazônia causou uma evasão fiscal estimada em 477 milhões de reais em 2009 (ADEODATO et al., 2013).

\section{CONCLUSÕES}

A proposta de desenvolvimento de PMFSPE mostrou o despertar do interesse dos extratores de madeira, sendo identificados 55 PMFSPE no município de BVR, em 2014. O modelo introduzido de MFC melhorou o capital natural e piorou o capital financeiro e físico, quando comparado à extração ilegal de madeira. As melhoras se referem ao controle de acesso aos recursos florestais, à conservação dos recursos manejados e à conservação da floresta. No entanto, a irregularidade da renda e a dependência de agentes externos para efetuarem a comercialização da madeira foram identificados como principais gargalos para viabilizar os PMFSPE. Os procedimentos estabelecidos pelo sistema DOF se mostraram inadequados à realidade de acesso e manuseio dos meios digitais experimentados pelos detentores de PMFSPE. Aproximadamente 1/3 dos extratores com PMFSPE chegaram ao objetivo final de comercializar a madeira manejada. Enquanto que para os extratores clandestinos a comercialização de madeira realizada é um processo simples de venda e compra, plenamente viável e condizente à realidade dos extratores, apesar do ônus ambiental e fiscal. 
Estratégias de fortalecimento do capital humano e do social como: a capacitação de recursos humanos, a valorização de conhecimentos tradicionais e o fortalecimento social dos grupos envolvidos, são ações preponderantes a serem realizadas pelos diversos atores envolvidos no processo e que podem levar a uma maior autonomia e empoderamento dos grupos diretamente envolvidos.

Visando equilibrar a balança entre os ganhos ambientais e as perdas financeiras dos projetos de PMFSPE, podem ser utilizadas estratégias como: fortalecimento do programa de governo de compra de móveis escolares (Preme), feitos por movelarias e com madeira manejada, visando promover as cadeias produtivas locais; e ampliar a abrangência do Programa Bolsa Floresta, um esquema de REDD+, já veiculado pelo Governo do Estado do Amazonas, para incluir detentores de PMFSPE.

\section{REFERÊNCIAS}

ADEODATO, S.; VILLELA, M.; BETIOL, L.S.; MONZONI, M. Madeira de ponta a ponta: o caminho desde a floresta até o consumo. São Paulo: FGV; RAE, 2013. 128 p.

AMARAL NETO, M.; CRUZ, H.; CARNEIRO, M.; MIRANDA, K. A construção de políticas públicas para o manejo florestal comunitário e familiar na Amazônia brasileira. In: CRUZ, H.; SABLAYROLLES, P.; KANASHIRO, M.; AMARAL, M.; SIST, P. (org.). Relação empresa/comunidade no contexto do manejo florestal comunitário e familiar: uma contribuição do projeto Floresta em Pé. Belém: IBAMA; DBFLO, 2011. p. 242-255.

AMAZONAS. Conselho Estadual do Meio Ambiente. Secretaria de Estado do Meio Ambiente. Resolução no 07 de 21 de junho 2011. Estabelece normas e procedimentos para plano de manejo florestal sustentável de pequena escala. Manaus: SEMA, CEMAAN, 2011.

BARBETT'TA, P.A. Estatística aplicada às ciências sociais. 8. ed. Florianópolis: UFSC, 2012.318 p.

BENATTI, J. H.; McGRATH, D. G.; OLIVEIRA, A. C. M. de. Políticas públicas e manejo comunitário de recursos naturais na Amazônia. Ambiente \& Sociedade, Campinas, v. 7, n. 2, p. 137-154, 2003. 
BERNARD, H. R. Research methods in anthropology: qualitative and quantitative approaches. 4. ed. New York: Altamira Press, 2006. 821 p.

BRASIL. Normas florestais federais para a Amazônia. Brasília: IBAMA; Diretoria de Uso Sustentável da Biodiversidade e Florestas, 2007. 414 p.

BRASIL. Casa Civil. Lei $\mathbf{n}^{\mathbf{0}}$ 12.651, de 25 de maio de 2012. Dispõe sobre a proteção da vegetação nativa e dá outras providências. Brasília: Casa Civil, 2012. CARVALHEIRO, K.; SABOGAL, C.; AMARAL, P. Análise da legislação para o manejo florestal por produtores de pequena escala na Amazônia brasileira. Belém: CIFOR: Projeto ForLive: IMAZON: UFRA, 2008. 100 p.

CARVALHO, R. S.; OLIVEIRA, A. D. Economic feasibility of timber management in extractive settlement projects of southwestern Amazonia. Cerne, Lavras, v. 16, n. 4, p. 505-516, 2010.

CHEN, H.; ZHU, T.; KROT'T, M.; CALVO, J. F.; GANESH, S. P.; MAKOTO, I. Measurement and evaluation of livelihoods assets in sustainable forest commons governance. Land Use Policy, Guildford, v. 30, p. 908-914, 2013.

DFID. DEPARTMENT FOR INTERNATIONAL DEVELOPMENT. Sustainable livelihoods guidance sheets (Sheet, 2). London: DFID, 1999. 22 p.

DYKSTRA, D. P. Reduced impact logging: concepts and issues. In: ENTERS, T., DURST, P. B.; APPLEGATE, G. B.; KHO, P.C.S.; MAN, G. (ed.). Applying reduced impact logging to advance sustainable forest management. Bangkok, Thailand: FAO, 2002. p. 23-39.

FEENY, D.; BERKES, F.; McCAY; ACHESON, J. M. A tragédia dos comuns: vinte e dois anos depois. In: DIEGUES, A. C.; MOREIRA, A. C. C. (org.). Espaços e recursos naturais de uso comum. São Paulo: USP, NUPAUB, 2001. p.17-42.

GIL, A. C. Métodos e técnicas de pesquisa social. 6. ed. São Paulo: Atlas, 2008. 220 p. Disponível em: https://ayanrafael.files.wordpress.com/2011/08/gil-a-cmc3a9todos-e-tc3a9cnicas-de-pesquisa-social.pdf. Acesso em: 18 maio 2014.

HAJJAR, R.; McGRATH, D. G.; KOZAK, R. A; INNES, J. L. Framing community forestry challenges with a broader lens: case studies from Brazilian Amazon. Journal of Environmental Management, London, v. 92, n. 9, p. 2159-2169, 2011. 
HARDIN, G. The tragedy of the commons. Science, Washington, v. 162, p. 1243-1248, 1968.

HUMPHRIES, S.; HOLMES, T.P.; KAINER, K.; KOURY, C.G.G.; CRUZ, E.; ROCHA, R.M. Are community-based forest enterprises in the tropics financially viable? Case studies from the Brazilian Amazon. Ecological Economics, Amsterdam, v. 77, n. 4 p. 62-73, 2012.

JONG, W de; CORNEJO, C.; PACHECO, P.; POKORNY, B.; STOIAN, D.; SABOGAL, C.; LOUMAN, B. Opportunities and challenges for community forestry: lessons from Tropical America. In:MERY, G.; KATILA, P.; GALLOWAY, G.; ALFARO, R.I.; KANNINEN, M.; LOBOVIKOV, M.; VARJO, J. (ed.), Forest and society: responding global drivers of change. Vienna: IUFRO 2010. chap. 16, p. 299-314. (World Series, 25).

KIBLER, J.F; SILVA, L.N. Articulação nacional e internacional no Projeto Floresta Viva. T\&C Amazônia, Manaus, v. 15, p. 35-43, 2008.

KOURY, C. G. G. Manejo florestal comunitário no baixo Amazonas: custos e entraves da produção madeireira. 2007. 129 f. Dissertação (Mestrado em Ciências das Florestas Tropicais) - Programa de Pós-Graduação em Ciências de Florestas Tropicais, Instituto Nacional de Pesquisas Amazônicas, Manaus, 2007.

KUSTERS, K.; BELCHER, B.; RUÍZ-PÉREZ, M.; ACHDIAWAN, R. A method to assess the outcomes of forest product trade on livelihoods and environment. Bogor: CIFOR, 2005. 26 p. (Working Paper, n. 32).

MACPHERSON, A. J.; SCHULZE, M. D.; CARTER, D. R.; VIDAL, E. A model for comparing reduced impact logging with conventional logging for an Eastern Amazonian Foresy. Forest Ecology and Manajement. Amsterdam, v. 260, n. 11, p. 2002-2011, 2010.

MEDINA, G.; POKORNY, B. Avaliação financeira do manejo florestal comunitário. Novos Cadernos NAEA, Belém, v. 14, n. 2, p. 25-36, 2011.

POKORNY, B.; JOHNSON, J. Community forestry in the Amazon: the unsolved challenge of forests and the poor. Natural Resources Perspectives, London, n. 112, 4 p., 2008.

RADACHOWSKY, J.; RAMOS, V. H.; McNAB, R.; BAUR, E. H.; KAZAKOV, N. Forest concessions in the Maya Biosphere Reserve, Guatemala: a decade later. Forest Ecology and Management, Amsterdam, v. 268, p. 18-28, 2012. 
STONE-JOVICICH, S.; AMARAL, P.; CRONKLETON, P.; FONSECA, H.; PIRES, A. Acompanhamento para manejo florestal comunitário na Reserva de Desenvolvimento Sustentável Mamirauá, Amazonas, Brasil. Bogor: CIFOR. 2007. 35 p.

SUNDERLIN, W.D. Poverty alleviation through community forestry in Cambodia, Laos, and Vietnam: an assessment of the potential. Forest Policy and Economics, Amsterdam, v. 8, p. 386-396, 2006.

VIANNA, A. L. M.; KOURY, C. G.; ARRUDA, A.; FERREIRA, D.; BARROS, H.; NOGUEIRA, O. Diagnóstico florestal do estado do Amazonas. Manaus: IDESAM, 2013. 76p.

WALDHOFF, P. Resultados da avaliação do manejo florestal comunitário sobre os meios de vida de seus protagonistas: destaque para conservação ambiental em detrimento a produção e autonomia. 2015. 150f. Tese (Doutorado em Ciências Florestais) - Escola Superior de Agricultura "Luiz de Queiroz", da Universidade de São Paulo, Piracicaba, 2014.

WALDHOFF, P.; VIDAL, E. Community loggers attempting to legalize traditional timber harvesting in the Brazilian Amazon: an endless path. Forest Policy and Economics, Amsterdam, v. 50, p. 311-318, 2015. 